\title{
Guy's Stone Score (GSS) Based on Intravenous Pyelogram (IVP) Findings Predicting Upper Pole Access Percutaneous Nephrolithotomy (PCNL) Outcomes
}

\author{
Bannakij Lojanapiwat, Pattara Rod-Ong, Pruit Kitirattrakarn, and Wilaiwan Chongruksut \\ Division of Urology, Department of Surgery, Faculty of Medicine, Chiang Mai University, Chiang Mai, Thailand \\ Correspondence should be addressed to Bannakij Lojanapiwat; dr.bannakij@gmail.com
}

Received 3 July 2016; Revised 4 October 2016; Accepted 2 November 2016

Academic Editor: James A. Brown

Copyright (C) 2016 Bannakij Lojanapiwat et al. This is an open access article distributed under the Creative Commons Attribution License, which permits unrestricted use, distribution, and reproduction in any medium, provided the original work is properly cited.

\begin{abstract}
Objective. To predict the success rate and complications following percutaneous nephrolithotomy via the upper pole using the Guy's Stone Score (GSS) based on the findings of a preoperative intravenous pyelogram (IVP). Patients and Methods. Two hundred and twenty-seven renal operations, which were carried out using PCNL via the upper pole, were classified according to the GSS assigned. Any complications were classified according to the Clavien classification. The success rates and incidence of any complications were compared between each GSS. Results. The immediate success rates were $87.50 \%$ of GSS1, 71.43\% of GSS2, 53.62\% of GSS3, and $38.46 \%$ of GSS4, $P<0.01$. There were statistically significant differences between the groups in stone size, overall immediate success rate, operative time, number of access tracts, and frequency of tubeless PCNL. Major complications (a Clavien score of 3-5) were significantly higher in the cases with a higher GSS. Conclusion. A GSS based on an IVP is a simple and reliable tool in predicting the success rate and possible complications following upper pole access PCNL.
\end{abstract}

\section{Introduction}

Percutaneous nephrolithotomy (PCNL) is accepted as being the first line treatment for large renal and upper ureteric stones. The advantage of upper pole access for percutaneous nephrolithotomy is good stone clearance due to its direct access to most intrarenal collecting systems $[1,2]$. Upper pole access can be achieved via both supracostal and subcostal routes. Due to the relative anatomic position of the upper pole of the kidney to the diaphragm and pleura, pulmonary complications are more common when this technique is used, especially of supracostal access $[1,2]$. Upper pole access PCNL should provide the same success rate in all stone patients but may experience more pulmonary complication.

Despite advances in technology and surgical techniques, in complex stone cases, the PCNL technique does not always result in the optimal goal of stone free status and increases the risk of significant complications. The information about the success rate and complications following this procedure is very important for both surgeons and patients in informing surgical planning and preoperative patient advice and counseling. At the current time, the Guy's Stone Scoring (GSS) system [3-7], the STONE nephrolithometry scoring system [8, 9], and the CROES (Clinical Research Office of Endourological Society) nomogram [10] are used for the prediction of the success rate and possible complications following PCNL in research and clinical practice. Previous studies reported that the Guy's stone score is significantly associated with stonefree status [3-7]; however other studies reported an association of this score with complications $[4,6]$. STONE nephrometric scores were significantly associated with stone free status but not with postoperative complications [8,9]. Most previous studies of GSS in PCNL treatment were performed in general PCNL patients [3-7].

This study focusses on the association of GSS based on an intravenous pyelogram (IVP) and on success rate and complications following PCNL via both supracostal and subcostal upper pole access. 


\section{Patients and Methods}

This study was approved for conduct clinical research from research committee of faculty of medicine, Chiang Mai University.

2.1. Patients. Two hundred and twenty-seven patients who underwent PCNL via upper pole access were recruited, including 146 subcostal access and 81 supracostal access cases. All patients with both kidney, ureter, bladder (KUB) film, and intravenous pyelogram (IVP) preoperatively were classified into 4 grades according to their Guy Stone Score (GSS):

(i) Guy's stone score 1 (GSS1): a solitary stone in the $\mathrm{mid} / \mathrm{and}$ or lower pole or in the renal pelvis with a normal anatomy and simple collecting system

(ii) Guy's stone score 2 (GSS2): a solitary stone in the upper pole; multiple stones in patients with simple anatomy; or a solitary stone in a patient with abnormal anatomy

(iii) Guy's stone score 3 (GSS3): multiple stones in a patient with abnormal anatomy or in a calyceal diverticulum or partial staghorn calculus

(iv) Guy's stone score 4 (GSS4): a complete staghorn calculus or any stone in a patient with spinal bifida or a spinal injury, calculus in patients with clinical neurological alternations (spinal cord injury, myelomeningocele)

Of the total 227 patients, the mean age was $54.28 \pm 13.34$, $51.77 \pm 10.07,55.12 \pm 0.92$, and $55.51 \pm 10.03$ years in GSS1, GSS2, GSS3, and GSS4, respectively. In the subgroup of patients who underwent supracostal access, the mean ages were $51.00 \pm 18.14,53.00 \pm 10.68,51.52 \pm 9.17$, and $53.24 \pm$ 9.29 years, respectively.

2.2. Methods. All procedures were carried out following the evaluation of hemostasis, renal function, and anatomy of collecting system by conventional serum laboratory techniques and intravenous pyelography. General anesthesia was administered. In the supine position, an open ended $6 \mathrm{Fr}$ ureteral catheter was placed transurethrally into the upper ureter or renal pelvis. All punctures were performed in the prone position at the upper pole (81 supracostal, 146 subcostal) after the injection of contrast media via the ureteric catheter under fluoroscopic guidance. All supracostal access was performed between the 11th and 12th rib into the lower part of the intercostal space with close coordination with the anesthesiologist for respiration control. The puncture was made through the retroperitoneum during full expiration, and the needle passed through the renal parenchyma into the collecting system during deep inspiration. Both working and safety guide wires were inserted after the needle was in collecting system. Tract dilatation was performed using an Amplatz dilator (Cook Urologic, Spencer, IN) or telescopic metal dilators size $8 \mathrm{Fr}$ to $30 \mathrm{Fr}$ followed by the Amplatz sheath 30 Fr. A standard 26 Fr nephroscope was used utilizing ultrasonic or pneumatic lithotripsy for stone disintegration. The collecting system was examined using fluoroscopy and direct inspection using a nephroscope at the end of the procedure. A 20 Fr nephrostomy tube was inserted for 4872 hours. No nephrostomy tube was inserted if there was no significant bleeding, no significant extravasation, no distal obstruction, and no retained stone (tubeless PCNL). Postoperative chest radiographs were obtained in all cases for the evaluation and treatment of any possible pulmonary complications in recovery room.

2.3. PCNL Outcome. The immediate success rate was defined as the patient being stone-free or the presence of asymptomatic fragments of less than or equal to $4 \mathrm{~mm}$ in plain KUB film postoperative day 1. Complications were graded according to the Clavien score system, which is divided into 5 grades. Minor complications were defined as Clavien score grades 1-2 and major complications were defined as Clavien 3-5.

2.4. Statistical Analysis. Statistical analysis using ANOVA Prosthoc and Fisher's exact test was performed, and $P<0.05$ was considered statistically significant.

\section{Results}

3.1. Total Patients $(N=277)$. The average stone size was $27.03 \pm 0.60 \mathrm{~mm}$ in GSS1, $26.42 \pm 10.09 \mathrm{~mm}$ in GSS2, $42.28 \pm$ $11.79 \mathrm{~mm}$ in GSS3, and $63.24 \pm 17.28 \mathrm{~mm}$ in GSS4, $P<$ 0.01. The operative time was $48.21 \pm 21.70 \mathrm{~min}$ in GSS1, $65.50 \pm 23.80 \mathrm{~min}$ in GSS2, $68.91 \pm 29.43 \mathrm{~min}$ in GSS3, and $76.30 \pm 33.40 \mathrm{~min}$ in GSS4, $P<0.01$. Tubeless PCNL was $18.75 \%, 20.0 \%, 8.7 \%$, and 5.49\%, in GSS1, GSS2, GSS3, and GSS4, respectively $(P=0.03)$. The immediate success rate was $87.50 \%$ in GSS1, $71.43 \%$ in GSS2, $53.62 \%$ in GSS3, and $38.46 \%$ in GSS4, $P<0.01$. Major complications (Clavien 3-5) were $3.13 \%, 17.14 \%, 30.43 \%$, and $29.67 \%$ in GSS1, GSS2, GSS3, and GSS4, respectively, $P<0.01$. There was no significant difference in age, number of incidents of previous open surgery, number of access tracts, and blood transfusion between each GSS. The demographic data with the results is shown in Tables 1 and 2.

3.2. Supracostal Access Patients $(N=81)$. The average stone size was $24.16 \pm 3.43 \mathrm{~mm}$ in GSS1, $27.00 \pm 9.15 \mathrm{~mm}$ in GSS2, $43.27 \pm 11.91 \mathrm{~mm}$ in GSS3, and $61.97 \pm 20.04 \mathrm{~mm}$ in GSS4, $P<0.01$. The immediate success rate was $83.33 \%$ in GSS1, $66.66 \%$ in GSS2, $64.00 \%$ in GSS3, and $34.14 \%$ in GSS4, $P<$ 0.01 . Major complications (Clavien 3-5) were 0\% in GSS1 and GSS2, $40 \%$ in GSS3, and $31.71 \%$ in GSS4, $P=0.03$. There was no significant difference in age, number of incidents of previous open surgery, number of access tracts, operative time, and rate of tubeless and blood transfusion between each GSS. The demographic data with the results is shown in Tables 3 and 4.

\section{Discussion}

PCNL via the upper pole was shown to achieve a greater stone free rate due to this technique being able to reach most of 
TABLE 1: The demographic data of total upper pole access patients $(N=227)$.

\begin{tabular}{|c|c|c|c|c|c|}
\hline & GSS1 & GSS2 & GSS3 & GSS4 & $P$ value \\
\hline & $N=32$ & $N=35$ & $N=69$ & $N=91$ & \\
\hline \multicolumn{6}{|l|}{ Age (year) } \\
\hline Mean (SD) & $54.28(13.34)$ & $51.77(10.07)$ & $55.52(0.961)$ & $55.51(10.03)$ & 0.13 \\
\hline \multicolumn{6}{|l|}{ Gender, $n(\%)$} \\
\hline Male: female & $12: 20$ & $21: 14$ & $48: 21$ & $62: 29$ & 0.01 \\
\hline Previous surgery, $n(\%)$ & $10(31.25)$ & $10(28.57)$ & $16(23.19)$ & $22(24.18)$ & 0.79 \\
\hline \multicolumn{6}{|l|}{ Stone side, $(N)$} \\
\hline Right : left & $17: 15$ & $15: 20$ & $37: 32$ & $50: 41$ & 0.67 \\
\hline \multicolumn{6}{|l|}{ Size (mm): } \\
\hline Mean (SD) & $27.03(0.60)$ & $26.42(10.09)$ & $42.28(11.79)$ & $63.24(17.28)$ & $<0.01$ \\
\hline \multicolumn{6}{|l|}{ BMI, $n(\%)$} \\
\hline $18-25 \mathrm{~cm} / \mathrm{kg}^{2}$ & $33(66.34)$ & $19(63.33)$ & $42(73.22)$ & $35(76.08)$ & 0.75 \\
\hline$>25 \mathrm{~cm} / \mathrm{kg}^{2}$ & $16(32.65)$ & $11(36.67)$ & $15(26.79)$ & $11(23.91)$ & \\
\hline \multicolumn{6}{|l|}{ Comorbidities } \\
\hline Diabetes, $n(\%)$ & $4(13.79)$ & $7(21.88)$ & $10(20.83)$ & $11(16.92)$ & 0.81 \\
\hline Hypertension, $n(\%)$ & $12(41.38)$ & $11(34.38)$ & $22(45.83)$ & $33(50.77)$ & 0.47 \\
\hline Dyslipidemia, $n(\%)$ & $7(24.14)$ & $6(18.75)$ & $8(16.67)$ & $15(23.08)$ & 0.81 \\
\hline \multicolumn{6}{|l|}{ Blood Cr., $n(\%)$} \\
\hline$<1.5 \mathrm{mg} \%$ & $43(78.18)$ & $23(74.19)$ & $53(88.33)$ & $40(74.07)$ & 0.22 \\
\hline$>1.5 \mathrm{mg} \%$ & $12(21.82)$ & $8(25.81)$ & 7 (11.67) & $14(25.93)$ & \\
\hline
\end{tabular}

TABLE 2: Outcomes of total upper pole access operations $(N=227)$.

\begin{tabular}{|c|c|c|c|c|c|}
\hline & $\begin{array}{c}\text { GSS1 } \\
N=32\end{array}$ & $\begin{array}{c}\text { GSS2 } \\
N=35\end{array}$ & $\begin{array}{c}\text { GSS3 } \\
N=69\end{array}$ & $\begin{array}{c}\text { GSS4 } \\
N=91\end{array}$ & $P$ value \\
\hline \multicolumn{6}{|l|}{ Number of access tracts, $n(\%)$} \\
\hline \multicolumn{6}{|l|}{ Mean (SD) } \\
\hline 1 & $31(96.88)$ & $33(94.29)$ & $61(88.41)$ & $82(90.11)$ & 0.48 \\
\hline$>1$ & $1(3.13)$ & $2(5.71)$ & $8(11.54)$ & $9(9.89)$ & \\
\hline \multicolumn{6}{|l|}{ Op. time (min) } \\
\hline mean $(\mathrm{SD})$ & $48.21(21.70)$ & $65.5(23.80)$ & $68.91(24.43)$ & $76.30(33.44)$ & $<0.01$ \\
\hline \multicolumn{6}{|l|}{ Blood transfusion } \\
\hline mean $(\mathrm{SD})$ & $1(3.13)$ & $3(8.57)$ & $4(5.80)$ & $4(4.40)$ & 0.76 \\
\hline Tubeless, $n(\%)$ & $6(18.75)$ & $7(20.00)$ & $6(8.70)$ & $5(5.49)$ & 0.03 \\
\hline \multicolumn{6}{|l|}{ Immediate success } \\
\hline$n(\%)$ & $28(87.50)$ & $25(71.43)$ & $37(53.62)$ & $35(38.46)$ & $<0.01$ \\
\hline \multicolumn{6}{|l|}{ Complications, $n(\%)$} \\
\hline Minor (Clavien 1-2) & $3(9.37)$ & $14(40.00)$ & $21(30.43)$ & $25(20.47)$ & $<0.01$ \\
\hline Major (Clavien 3-5) & 0 & $2(5.70)$ & $7(10.14)$ & $13(16.48)$ & $<0.01$ \\
\hline Sepsis & 0 & 1 & 5 & 5 & \\
\hline Pulmonary complication & 0 & 1 & 1 & 5 & \\
\hline Other & 0 & 0 & 1 & 3 & \\
\hline \multicolumn{6}{|l|}{ Auxiliary treatment and } \\
\hline re-PCNL, $n(\%)$ & $2(6.25)$ & $1(2.86)$ & $18(25.99)$ & $38(41.75)$ & 0.02 \\
\hline
\end{tabular}


TABLE 3: The demographic data of supracostal upper access patients $(N=81)$.

\begin{tabular}{|c|c|c|c|c|c|}
\hline & GSS1 & GSS2 & GSS3 & GSS4 & $P$ value \\
\hline & $N=6$ & $N=9$ & $N=25$ & $N=41$ & \\
\hline \multicolumn{6}{|l|}{ Age (year), } \\
\hline Mean (SD) & $51(18.14)$ & $53(10.68)$ & $51.52(9.17)$ & $53.24(9.29)$ & 0.11 \\
\hline \multicolumn{6}{|l|}{ Gender, $(N)$} \\
\hline Male : female & $1: 5$ & $8: 1$ & $16: 9$ & $32: 9$ & 0.01 \\
\hline Previous surgery, $N(\%)$ & $1(16.67)$ & $1(11.11)$ & $5(20.00)$ & $11(26.83)$ & 0.81 \\
\hline \multicolumn{6}{|l|}{ Stone side, $N(\%)$} \\
\hline Right: left & $31: 25$ & $14: 18$ & $29: 34$ & $27: 29$ & 0.72 \\
\hline \multicolumn{6}{|l|}{ Size $(\mathrm{mm})$} \\
\hline Mean (SD) & $24.16(3.43)$ & $7(9.15)$ & 43.27 (11.91) & $61.97(20.04)$ & $<0.01$ \\
\hline \multicolumn{6}{|l|}{ BMI } \\
\hline $18-25 \mathrm{~cm} / \mathrm{kg}^{2}$ & $3(50.00)$ & $6(75.00)$ & $13(68.42)$ & $23(65.76)$ & 0.91 \\
\hline$>25 \mathrm{~cm} / \mathrm{kg}^{2}$ & $3(50.00)$ & $2(25.00)$ & $6(31.58)$ & $10(31.25)$ & \\
\hline \multicolumn{6}{|l|}{ Comorbidities } \\
\hline Diabetes, $n(\%)$ & $1(16.67)$ & $2(25.00)$ & $5(33.33)$ & $6(20.00)$ & 0.76 \\
\hline Hypertension, $n(\%)$ & $3(50.00)$ & $2(25.00)$ & $6(40.00)$ & $15(50.00)$ & 0.62 \\
\hline Dyslipidemia, $n(\%)$ & $2(33.30)$ & $1(12.50)$ & $2(13.33)$ & $7(23.33)$ & 0.67 \\
\hline \multicolumn{6}{|l|}{ Blood Cr. } \\
\hline$<1.5 \mathrm{mg} \%$ & $5(83.33)$ & $5(62.50)$ & $17(77.27)$ & $26(65.00)$ & 0.63 \\
\hline$>1.5 \mathrm{mg} \%$ & $1(16.67)$ & $3(37.50)$ & $5(22.73)$ & $14(35.00)$ & \\
\hline
\end{tabular}

TABLE 4: Outcomes of supracostal upper pole access operations $(N=81)$.

\begin{tabular}{|c|c|c|c|c|c|}
\hline & $\begin{array}{c}\text { GSS1 } \\
N=6\end{array}$ & $\begin{array}{l}\text { GSS2 } \\
N=9\end{array}$ & $\begin{array}{c}\text { GSS3 } \\
N=25\end{array}$ & $\begin{array}{c}\text { GSS4 } \\
N=41\end{array}$ & $P$ value \\
\hline \multicolumn{6}{|l|}{ Operative time (min) } \\
\hline Mean (SD) & $50.57(20.31)$ & $67(24.50)$ & $68.46(23.00)$ & $78.71(35.09)$ & 0.17 \\
\hline \multicolumn{6}{|l|}{ Number of access tracts } \\
\hline 1 & $6(100.00)$ & $8(88.89)$ & $23(92.00)$ & $39(95.12)$ & 0.68 \\
\hline$>1$ & $0(0.00)$ & $1(11.11)$ & $2(8.00)$ & $2(4.88)$ & \\
\hline Immediate success rate $n(\%)$ & $5(83.33)$ & $6(66.66)$ & $16(64.0)$ & $14(34.14)$ & $<0.01$ \\
\hline Blood transfusion $n(\%)$ & $1(16.67)$ & $1(11.11)$ & $2(8.00)$ & $2(4.88)$ & 0.41 \\
\hline \multicolumn{6}{|l|}{ Complications, $n(\%)$} \\
\hline Minor (Clavien 1-2) & $0(0)$ & $4(33.33)$ & $8(32.00)$ & $5(12.19)$ & \\
\hline Major (Clavien 3-5) & $0(0)$ & $1(11.11)$ & $5(20.00)$ & $12(29.20)$ & 0.03 \\
\hline Sepsis & 0 & 0 & 2 & 4 & \\
\hline Pulmonary complication & 0 & 1 & 1 & 6 & \\
\hline Other & 0 & 0 & 2 & 2 & \\
\hline Auxiliary treatment and re-PCNL, $n(\%)$ & $1(16.67)$ & $0(0)$ & $8(32.00)$ & $15(36.58)$ & 0.21 \\
\hline
\end{tabular}

the intrarenal collecting system especially in the treatment of complex stones. The incidence of pulmonary complication is significantly higher in PCNL via upper pole access especially when access is the supracostal route.

Several factors are associated with post-PCNL outcomes including stone size, stone burden, degree of hydronephrosis, history of previous open nephrolithotomy, and anomalies of the kidney [11-14]. de la Rosette et al. reported the increase of complications when PCNL was performed in patients who had larger stones [15]. In contrast, Olbert et al. found that the increase in the size of the stone did not relate to postoperative stone free status and complication rate but did relate to operative time and length of hospital stay [16]. Turna et al. reported that only stone composition was related to blood loss [12]. Penbegul et al. report the same outcomes following PCNL in patients with or without abnormal renal anatomy $[13,14]$.

Previously, there was no definite tool to predict PCNL outcome and rate of complication, which is very important to both physicians and patients. The tools should indicate 
the difficulty or risk related to the surgery, which is the information required for patient counseling and surgeon communication. Several studies have attempted to classify PCNL to predict the outcomes $[11,12,16,17]$ and complications [16-20]. Most of these studies did not result in any consistent correlation as regards predictions and none of these are in common use in clinical practice. A quick, simple, and reproducible tool is needed in real life practice to predict outcomes and complications following PCNL. This is very important for patient counseling, surgeon training, and service planning.

Recently, urolithiasis scoring systems for percutaneous nephrolithotomy outcome have been developed including the Guy Stone Score (GSS), STONE nephrometry and the CROES nephrolithometric nomogram. The Guy Stone Score, STONE nephrometry, and CROES nomogram serve as disease stratification tools for surgical planning and patient counseling in aspects of surgical outcome, but only Guy's Score and STONE nephrometry are associated with possible complications.

Guy Stone Score (GSS) is a simple and reliable tool for predicting success rate. GSS is mainly used in kidney, ureter, bladder (KUB) film, and intravenous urography (IVU) to predict the success rate following PCNL. Some studies reported the usage of computed tomographic scan in GSS estimation for more accuracy. The CT scan was used as the preoperative investigation in stone patients, which improved the accuracy of stone information and renal and collecting system anatomy $[4,5]$. Vicentini and colleagues used Guy's Stone Score (GSS) to predict percutaneous nephrolithotomy outcomes in the supine position based on preoperative computed tomographic scan in 155 renal cases. They confirmed the usefulness of the GSS tool based on CT findings in the accuracy of evaluation of renal stones in respect of surgical outcome and complications [4].

We agree that a preoperative CAT scan provided more accuracy regarding the detail of the anatomy such as characterization of the stone and pelvicalyceal anatomy, which are the factors in scoring these tools. But, GSS with plain KUB and intravenous urography is inexpensive and is a common routine investigation in stone patients especially in developing countries with a high prevalence of stone disease. These investigations have the additional advantage of providing a lower radiation dose than a CT scan. This is the initial study reporting on the use of GSS based on IVP in prediction regarding the outcome of PCNL with upper pole access, either supracostal or subcostal access.

This study confirmed that GSS based on KUB and intravenous urography is a valuable tool in the prediction of the outcome and complication rate following PCNL via the upper pole. Immediate success rates, operative time, tubeless rates (rate of uncomplicated procedure), and major complications are significantly different within the group of each GSS. There was few patients in this study who need multiple tracts and received blood transfusion. Fewer numbers of all positive outcome parameters and more major complications were found in higher GSS patients. A preoperative CT scan is not a common investigation in developing countries. The information in grading patients of GSS can be achieved from plain KUB and intravenous urography due to its simple classification in routine clinical practice. This nomogram does not need complex calculations. Our study demonstrated that plain KUB and intravenous urography are as useful in informing the classification grading of the GSS score as the CT scan. The results of this study demonstrates the correlation of the GSS grade with post-upper pole access PCNL outcome and complications in a large number of patients.

The Limitations. The number of patients in this study is small especially with supracostal access in GSS1 and GSS2. This limitation can be explained by the less common use of supracostal access in patients with lower GSS. A future larger prospective or meta-analysis study is needed. This study did not recruit patients with other factors such as kidney anomalies that may affect the outcome. Only Guy's Stone Score (GSS) was utilized in this study based on an intravenous pyelogram (IVP) to predict the outcome, so it cannot be compared with other Stone Scores, which required a CAT scan.

\section{Conclusion}

Guy's Stone Score (GSS) based on interpretation of an intravenous pyelogram is a simple and reliable tool in predicting the immediate success rate and possible complications following supracostal and subcostal upper pole access PCNL. This nomogram is very helpful in preoperative patient counseling and informing the decision about referral of more complicated patients to centers with higher patient volume and more expertise.

\section{Competing Interests}

All authors declare that there is no conflict of interests.

\section{Acknowledgments}

This work was supported by Faculty of Medicine, Chiang Mai University, Chiang Mai, Thailand.

\section{References}

[1] B. Lojanapiwat and S. Prasopsuk, "Upper-pole access for percutaneous nephrolithotomy: comparison of supracostal and infracostal approaches," Journal of Endourology, vol. 20, no. 7, pp. 491-494, 2006.

[2] R. N. Pedro and N. R. Netto Jr., "Upper-pole access for percutaneous nephrolithotomy," Journal of Endourology, vol. 23, no. 10, pp. 1645-1647, 2009.

[3] K. Thomas, N. C. Smith, N. Hegarty, and J. M. Glass, "A costeffective smoothed multigrid with modified neighborhoodbased aggregation for Markov Chains," Urology, vol. 78, no. 2, pp. 277-15, 2011.

[4] F. C. Vicentini, G. S. Marchini, E. Mazzucchi, J. F. A. Claro, and M. Srougi, "Utility of the Guy's stone score based on computed tomographic scan findings for predicting percutaneous 
nephrolithotomy outcomes," Urology, vol. 83, no. 6, pp. 12481253, 2014.

[5] J. P. Ingimarsson, L. M. Dagrosa, E. S. Hyams, and V. M. Pais, "External validation of a preoperative renal stone grading system: reproducibility and inter-rater concordance of the Guy's stone score using preoperative computed tomography and rigorous postoperative stone-free criteria," Urology, vol. 83 , no. 1 , pp. 45-49, 2014.

[6] S. Mandal, A. Goel, R. Kathpalia et al., "Prospective evaluation of complications using the modified Clavien grading system, and of success rates of percutaneous nephrolithotomy using Guy's Stone Score: a single-center experience," Indian Journal of Urology, vol. 28, no. 4, pp. 392-398, 2012.

[7] B. R. Matlaga and E. S. Hyams, "Stones: can the Guy's stone score predict PNL outcomes?" Nature Reviews Urology, vol. 8, no. 7, pp. 363-364, 2011.

[8] Y. A. Noureldin, M. A. Elkoushy, and S. Andonian, "Which is better? Guy's versus S.T.O.N.E. nephrolithometry scoring systems in predicting stone-free status post-percutaneous nephrolithotomy," World Journal of Urology, vol. 33, no. 11, pp. 18211825, 2015.

[9] Z. Okhunov, M. Helmy, A. Perez-Lansac et al., "Interobserver reliability and reproducibility of S.T.O.N.E. nephrolithometry for renal calculi," Journal of Endourology, vol. 27, no. 10, pp. 1303-1306, 2013.

[10] A. Smith, T. D. Averch, K. Shahrour et al., "A nephrolithometric nomogram to predict treatment success of percutaneous nephrolithotomy," Journal of Urology, vol. 190, no. 1, pp. 149-156, 2013.

[11] H.-G. Tiselius and A. Andersson, "Stone burden in an average Swedish population of stone formers requiring active stone removal: how can the stone size be estimated in the clinical routine?" European Urology, vol. 43, no. 3, pp. 275-281, 2003.

[12] B. Turna, M. Umul, S. Demiryoguran, B. Altay, and O. Nazli, "How do increasing stone surface area and stone configuration affect overall outcome of percutaneous nephrolithotomy?" Journal of Endourology, vol. 21, no. 1, pp. 34-43, 2007.

[13] N. Penbegul, N. K. Hatipoglu, M. N. Bodakci et al., "Role of ultrasonography in percutaneous renal access in patients with renal anatomic abnormalities," Urology, vol. 81, no. 5, pp. 938942, 2013.

[14] P. J. Osther, H. Razvi, E. Liatsikos et al., "Percutaneous nephrolithotomy among patients with renal anomalies: patient characteristics and outcomes; A subgroup analysis of the clinical research office of the endourological society global percutaneous nephrolithotomy study," Journal of Endourology, vol. 25, no. 10, pp. 1627-1632, 2011.

[15] J. J. M. C. H. de la Rosette, M. P. Laguna, J. J. Rassweiler, and P. Conort, "Training in percutaneous nephrolithotomy-a critical review," European Urology, vol. 54, no. 5, pp. 994-1003, 2008.

[16] P. J. Olbert, A. Hegele, A. J. Schrader, A. Scherag, and R. Hofmann, "Pre- and perioperative predictors of short-term clinical outcomes in patients undergoing percutaneous nephrolitholapaxy," Urological Research, vol. 35, no. 5, pp. 225-230, 2007.

[17] A. Y. Muslumanoglu, A. Tefekli, M. A. Karadag, A. Tok, E. Sari, and Y. Berberoglu, "Impact of percutaneous access point number and location on complication and success rates in percutaneous nephrolithotomy," Urologia Internationalis, vol. 77, no. 4, pp. 340-346, 2006.
[18] K. Labadie, Z. Okhunov, A. Akhavein et al., "Evaluation and comparison of urolithiasis scoring systems used in percutaneous kidney stone surgery," Journal of Urology, vol. 193, no. 1, pp. 154-159, 2015.

[19] A. R. El-Nahas, A. A. Shokeir, A. M. El-Assmy et al., "Postpercutaneous nephrolithotomy extensive hemorrhage: a study of risk factors," Journal of Urology, vol. 177, no. 2, pp. 576-579, 2007.

[20] A. Tefekli, M. A. Karadag, K. Tepeler et al., "Classification of percutaneous nephrolithotomy complications using the modified clavien grading system: looking for a standard," European Urology, vol. 53, no. 1, pp. 184-190, 2008. 


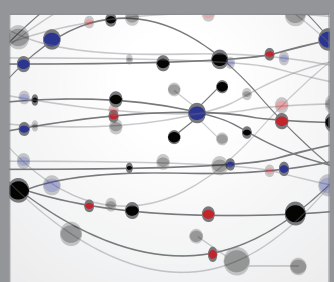

The Scientific World Journal
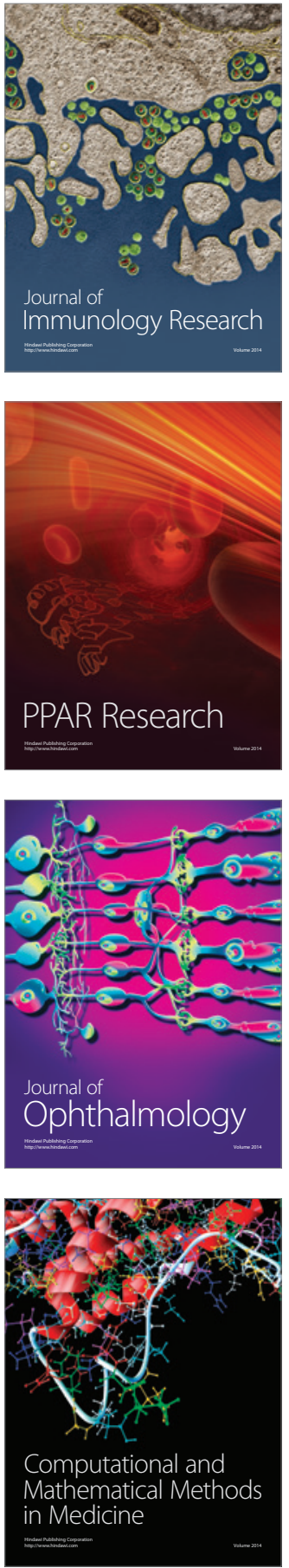

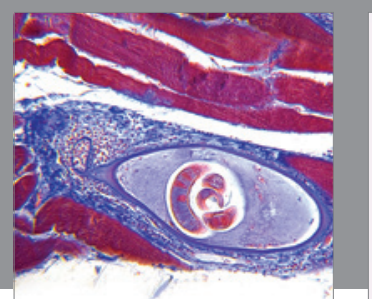

Gastroenterology Research and Practice

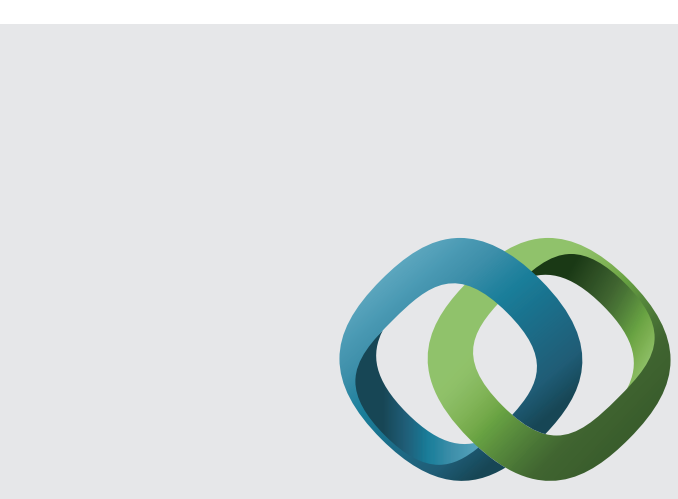

\section{Hindawi}

Submit your manuscripts at

http://www.hindawi.com
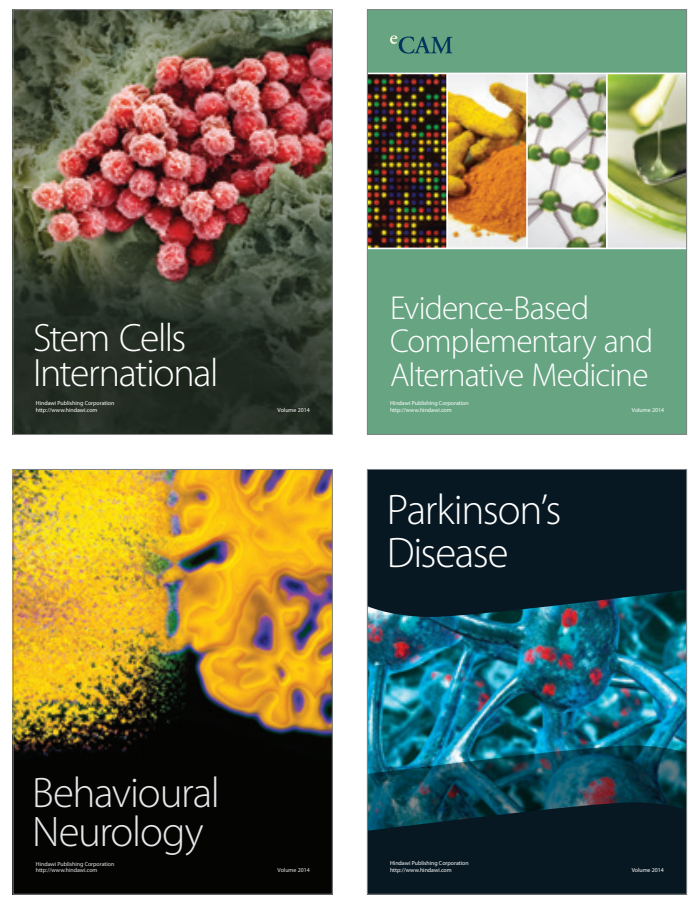
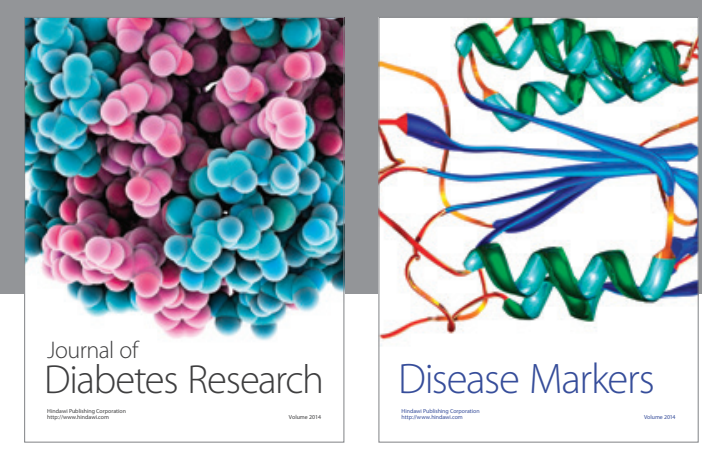

Disease Markers
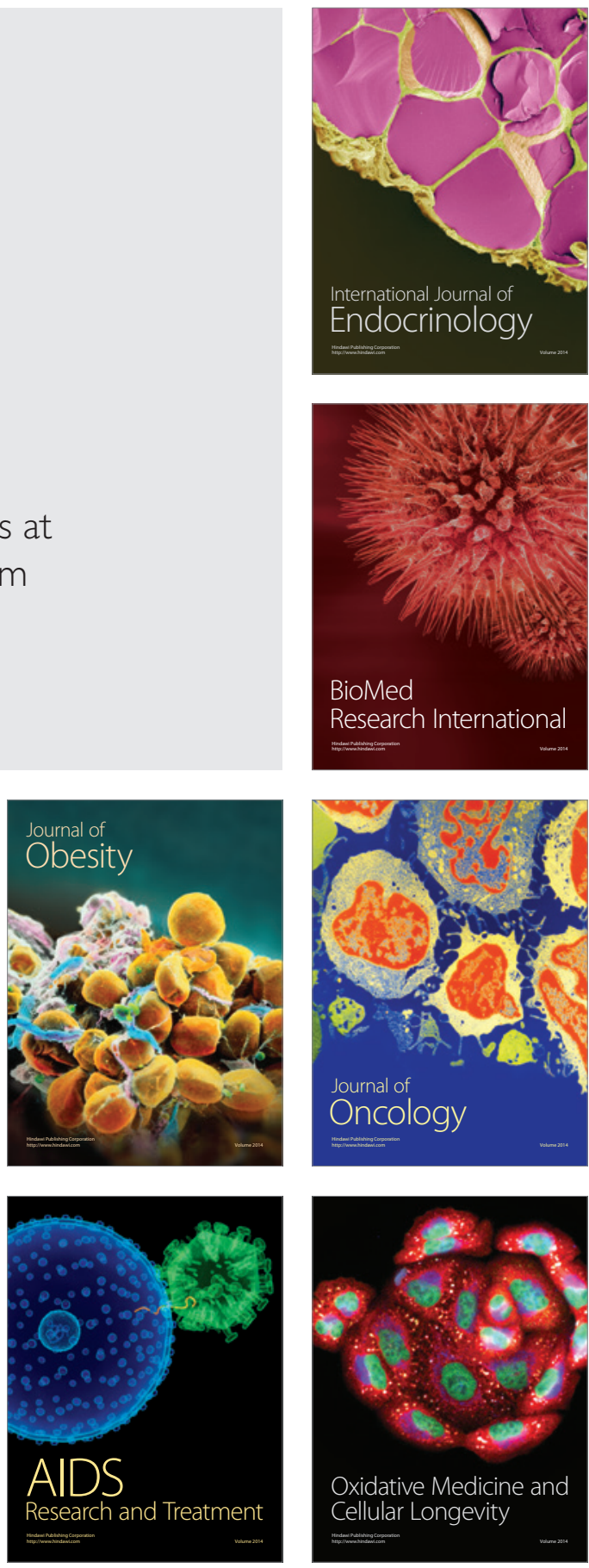